\title{
Increased Risk of High Birthweight in Singleton Newborns after Frozen-Thawed Embryo Transfer According to Endometrial Preparation, Ovulatory or Artificial Cycle
}

\author{
Sylvie Epelboin ${ }^{1 *}$, Julie Labrosse', Emmanuel Devouche², Solene Gricourt ${ }^{1}$, Dominique Luton ${ }^{1}$, Xavier Ferraretto ${ }^{3}$, \\ Maeliss Peigné ${ }^{4}$
}

\begin{abstract}
${ }^{1}$ AP-HP. Nord - Université de Paris, Unité de Médecine de la Reproduction, Service de Gynécologie-Obstétrique, Hôpital Bichat-Claude Bernard, 46 rue Henri Huchard, 75018 Paris, France ; sylvie.epelboin@aphp.fr; solenne.gricourt@aphp.fr; dominique.luton@aphp.fr

2Université de Paris, Laboratoire Psychopathologie et Processus de Santé (EA4057), 71, avenue Edouard Vaillant, 92774 Boulogne-Billancourt, France ; devouche7@gmail.com

${ }^{3}$ AP-HP. Nord - Université de Paris, Service de Biologie de la Reproduction, Hôpital Bichat-Claude Bernard, 46 rue Henri Huchard, 75018 Paris, France; xavier.ferraretto@aphp.fr

${ }^{4}$ AP-HP- Université Sorbonne Paris Nord Service de Médecine de la Reproduction et préservation de la fertilité, Hôpital Jean Verdier, Avenue du 14 juillet, Bondy, 93140, France ; julie.labrosse@aphp.fr; mae-

liss.peigne@aphp.fr;

*Correspondence: e-mail: sylvie.epelboin@aphp.fr; Tel: +33140256497
\end{abstract}

\begin{abstract}
:
Background: It is unknown whether prolonged artificial hormonal environment during early fetal development affects the birthweight of singletons born after frozen-thawed embryo transfer (FET).

Methods: A retrospective observational study included singleton births $>22$ weeks of gestation obtained after FET between 2013-2019, after endometrial preparation with ovulatory cycle (OC) or artificial cycle (AC). Our primary objective was to compare birthweight of singletons after FET between endometrial preparation by OC or AC. Secondary objectives included prolonged pregnancies, high birthweight, low birthweight, SGA and LGA rates. Multivariate analyses were performed considering potential confounding factors.

Results: Among 198 singleton live births after FET, 112 were obtained with OC and 86 with AC. Prolonged pregnancies rate was higher in AC ( $25.6 \%$ vs. $7.1 \%$, respectively, $p=0.001)$. Mean birthweight was higher $(+219 \mathrm{~g})$ in AC (3386g vs. 3167g, $p=0.01$; adjusted- $p=0.052)$, as well as the rate of babies exceeding $4000 \mathrm{~g}(16.3 \%$ vs. $2.7 \%$, $p=0.03$, adjusted- $p=0.015)$. The rate of babies $<2500 \mathrm{~g}$ was lower in AC $(3.5 \%$ vs. $11.6 \%$, respectively, $p=0.050$, adjusted- $p=0.049$ ).

Conclusions: Since OC does not strain the chances of pregnancy and in the incomplete knowledge of the consequences of neonatal overweight on the future health of children, OC preparation could be advocated as first-line endometrial preparation in FET.
\end{abstract}

Keywords: Frozen-Thawed Embryo Transfer; Birthweight; Endometrial Preparation; Ovulatory Cycle; Artificial Cycle

\section{Introduction}

More than 35 years after the first successful pregnancy from a frozen-thawed embryo transfer (FET) [1], the practice of FET has increased. In French registers, FET represented 
$37.4 \%$ of IVF attempts in 2017, versus 30.9\% in 2014 [2,3]. Developments in cryopreservation methods, higher rates of elective single embryo transfers (e-SET) and "freeze-all" policies have also promoted embryo freezing [4-6].

Besides embryo survival and quality, successful FET relies on endometrial receptivity at the time of transfer. The most common protocols for endometrial preparation are: (1) the artificial cycle (AC), and (2) the ovulatory cycle (OC), either natural cycle (NC) or mild ovarian stimulated (OS) cycle. In OC, a luteal phase support using progesterone can be prescribed but a corpus luteum (CL) naturally secretes progesterone, enabling endometrial receptivity for implantation. In $\mathrm{AC}$, estrogen and progesterone supplementation are mandatory since no CL exists, and is continued up to 12 weeks in case of pregnancy. The choice of the best protocol is still debated. While studies reported equally successful pregnancy rates (PR), ongoing pregnancy rates (OPR) and live birth rates (LBR) between protocols in women with regular cycles [7-9], a recent systematic review and meta-analysis [10] suggested mild OS as a promising option since PR and LBR were higher compared to AC. We recently published data showing that OC was associated to higher LBR compared to AC in multivariate analysis [11].

Hence, it seems that the choice of the best protocol should consider obstetric and neonatal outcomes [12]. Numerous studies have indicated that newborns conceived after IVF and immediate transfer (so-called "fresh") had lower average weights compared to natural conception, even for singletons. Subsequently, birthweight, macrosomia (birthweight $>4000 \mathrm{~g}$ ), and Large for Gestational Age syndrome (LGA) (birthweight $>90$ th percentile for gestational age) were reported to be higher in children born after FET compared to fresh transfer, regardless of techniques used [13-22]. However, the underlying mechanisms are still poorly understood [15,23-27]. Characteristics of the cellular process of fetal growth and epigenetic regulation during pre-implantation are still in question [28]. Intrauterine growth potential may be affected by epigenetic changes in the early embryonic stages during freezing and thawing [29]. Biological conditions (IVF technique, culture medium, embryonic stage) may play a role. A study led by Pinborg et al. [21] reported higher LGA and macrosomia rates in FET vs. fresh transfer, even after adjustment for birth order, suggesting that results could not only be explained by being the second born or by intrinsic maternal factors, but may also be related to freezing/thawing procedures per se. Altogether, whether the periconceptional hormonal environment induced by endometrial preparation protocols for FET has an impact on birthweight remains to be elucidated. A recent study suggested that the absence of CL in $\mathrm{AC}$ may play a role in the increased risk of hypertensive disorders during pregnancy [30]. Another study concluded that placental volume and other 1st trimester parameters were modified by IVF with fresh embryo transfer or FET compared to spontaneous conceptions, but with opposite trends, and that hormonal treatment per se may have a major effect on pregnancy outcomes through the modification of placental invasiveness [31]. LGA, as Small for Gestational Age (SGA) (birthweight <10th percentile for gestational age), are at increased risk of complications in subsequent developmental delay or mortality [32-34]. 
Identifying and quantifying these events aims to anticipate the consequences at an individual level and try to identify their causes [15,23-27].

The main objective of this monocentric retrospective study was to compare the birthweight of singletons conceived after FET between endometrial preparation by OC or AC in daily clinical practice. The secondary objectives were to compare prolonged pregnancies high birthweight, low birthweight, SGA and LGA rates between these two groups and to evaluate whether endometrial preparation was predictive of these neonatal outcomes.

\section{Materials and Methods}

\subsection{Endometrial preparation protocols}

The choice of endometrial preparation protocol depended on the physician's decision. The 2 endometrial preparation protocols were:

- OC: gonadotropin stimulation (37.5 to 75 IU) was initiated between cycle Day 2 (if oligo-anovulatory) and 10, Day 5 for most ovulatory women. A GnRH antagonist could be used to program FET. Ultrasound and hormonal testing (estradiol, progesterone and LH) was performed Day 8 to 11 and repeated if needed. Once the dominant follicle reached $16-20 \mathrm{~mm}$, ovulation was induced (6500 UI r-hCG: Ovitrelle ${ }^{\circledR}$, Merck, Germany). Then, a luteal phase support with vaginal micronized progesterone (VMPg), $200 \mathrm{mg} /$ day, was administered for maximum 6 weeks of gestation (WG) if pregnancy, since the major source of progesterone derived from the CL. FET was performed 5 days after r-hCG injection for cleaved embryos and 7 days after for blastocysts.

- AC: endometrial preparation started on Day 1 with estradiol (E2) administrated orally at $4-6 \mathrm{mg} /$ day or transdermally $(200 \mu \mathrm{g} / 3$ days).The few for which $\mathrm{GnRH}$ agonist was co-prescribed started E2 substitution 10 days after agonist introduction. Ultrasound and hormonal testing were performed Days 12- 14 and repeated if needed. When endometrial thickness reached $7 \mathrm{~mm}$ and serum progesterone level $<1 \mathrm{ng} / \mathrm{ml}$, VMPg (600 mg daily) was administered ( 3 and 5 days before FET for cleaved embryos or blastocysts respectively) until the 12th WG if pregnancy.

\subsection{Embryos}

Embryos were obtained from conventional IVF or ICSI cycles. Egg donation cycles were not included. Embryos were mainly frozen at cleavage stage until April 2016, then at blastocyst stage after evolution of laboratory policy. Cleaved embryos were considered alive if at least $50 \%$ blastomeres were intact after thawing. 


\subsection{Births}

All live births > 22 WG were included. Medical terminations of pregnancies and antenatal deaths were excluded. No perinatal deaths were reported. Premature delivery was defined as $<37$ WG. Prolonged pregnancies were considered for terms $>41 W G$ [35].

Macrosomia was defined for any child born at term $>4000 \mathrm{~g}$. SGA and LGA were defined as birthweight $<10$ th or $>90$ th percentile for gestational age, respectively.

\subsection{Statistics}

Descriptive and regression analyses were performed using Stata for Windows (version 14; StataCorp). Paternal and maternal ages at freezing, maternal smoking status, body mass index, PCOS, parity, technique (IVF/ICSI), embryo stage and freezing technique were included in the multiple regression model as potential confounders.

\subsection{Ethics}

The Ethical committee gave its unrestricted approval for the study and all patients had previously given their consent to use their data (CEERB Paris Nord, IRB 00006467: ID 2018013). All data were collected from Medifirst ${ }^{\circledR}$ software, meeting recognized medical and ethical specifications according to the French information protection commission (ID 2068638).

\section{Results}

Among the 198 singletons born after FET during the 5-year study period (2013- 2018), 112 were conceived with $\mathrm{OC}$ and 86 with $\mathrm{AC}$, respectively. No difference was observed concerning parental characteristics, except for PCOS (more frequent in AC, $p=0.002$ ). Regarding embryonic characteristics, higher rates of blastocysts and freezing by vitrification were observed for OC (Table 1).

Table 1. Parental and embryonic characteristics 
Maternal age at freezing

Maternal age at transfer

Maternal age at birth

Paternal age at freezing

BMI $(\mathrm{kg} / \mathrm{m} 2)$

Smoking

Primary infertility

$\geq 2$ miscarriages

IVF indication

Endometriosis

Tubal infertility

PCOS

Male infertility

Delivery characteristics

Primiparous

C-section

$$
32.8(4.5)
$$

$34.0(4.2)$

$34.7(4.2)$

$38.7(7.7)$

$25.0(4.0)$
$33.1(4.1)$

$33.6(4.5)$

$34.4(4.5)$

$38.7(4.5)$

$25.3(4.8)$
0.62

0.54

0.55

0.98

0.59

0.65

0.72

0.14

17 (15.2)

14 (12.5)

42 (37.5)

14 (12.5)

65 (58.0)

9 (10.7)

$40(46.5)$

$7(8.1)$

15 (17.4)

$24(27.9)$

27 (31.4)

$43(50.0)$

0.33

0.16

0.002

0.26
Duration of storage (days)

$\begin{array}{rr}<90 & 41(36.6) \\ 90-365 & 46(41.1) \\ 365-1095 & 16(14.3) \\ >1095 & 9(8.0)\end{array}$

69 (80.2)

$21(24.4)$

$30(34.9)$

34 (39.5)

64 (74.4)

0.020
31 (36.1) 0.88

35 (40.7)

15 (17.4)

5 (5.8)

49 (37.7)

0.79
0.25

0.10

0.42

0.028

62 (59.6)

Abbreviations: ovulatory cycle (OC); artificial cycle (AC); in vitro fertilisation (IVF); polycystic ovarian syndrome (PCOS); standard (Std)

Concerning birth outcomes, there was no difference in gender, mean gestational age or preterm birth. Prolonged pregnancies rate was higher in AC (25.6\% vs. 7.1\%, respectively, $p$ and adjusted- $p=0.001)$. Mean birthweight was significantly higher in AC (3386g vs. 3167g, difference: $+219 \mathrm{~g} ; p=0.010$; adjusted- $p=0.052)$ (Table 2).

Table 2: Neonatal outcomes in ovulatory and artificial cycles 


\begin{tabular}{|c|c|c|c|c|c|}
\hline \multirow[t]{2}{*}{ Variable } & \multicolumn{3}{|c|}{ Protocol } & & \multirow[t]{2}{*}{$p$-value } \\
\hline & OC $(n=112)$ & & $\mathrm{AC}(\mathrm{n}=86)$ & & \\
\hline & mean (SD) & n $(\%)$ & mean (SD) & $\mathrm{n}(\%)$ & \\
\hline Male sex & & $53(47.3)$ & & $40(46.5)$ & 0.91 \\
\hline Gestational age, $\mathrm{WG}+\mathrm{D}$ & $39+1(2+0)$ & & $39+5(2+2)$ & & 0.064 \\
\hline \multicolumn{6}{|l|}{ Preterm birth } \\
\hline$<37$ weeks & & $10(8.9)$ & & $3(3.5)$ & 0.14 \\
\hline$<32$ weeks & & $2(1.8)$ & & $2(2.3)$ & 0.79 \\
\hline \multicolumn{6}{|c|}{ Prolonged pregnancy } \\
\hline$>41$ weeks & & $8(7.1)$ & & $22(25.6)$ & 0.001 \\
\hline$>42$ weeks & & $1(12,5)$ & & $5(22.7)$ & 0.54 \\
\hline Height, $\mathrm{cm}$ & $49.7(3.0)$ & & $49.0(3.1)$ & & 0.20 \\
\hline Birthweight, $g$ & 3167 (557) & & $3386(619)$ & & 0.010 \\
\hline$<1500 \mathrm{~g}$ & & $1(0.9)$ & & $2(2.3)$ & 0.43 \\
\hline$<2500 \mathrm{~g}$ & & 13 (11.6) & & $3(3.5)$ & 0.050 \\
\hline$>4000 \mathrm{~g}$ & & $3(2.7)$ & & $14(16.3)$ & 0.003 \\
\hline$>4500 \mathrm{~g}$ & & 0 & & $3(3.5)$ & NA \\
\hline SGA & & $11(9.8)$ & & $8(9.3)$ & 0.90 \\
\hline LGA & & $12(10.7)$ & & $13(15.1)$ & 0.36 \\
\hline
\end{tabular}

aAdjusted on paternal and maternal age at freezing, maternal smoking status, body mass index

Abbreviations: PCOS, parity and technique (IVF/ICSI), embryo stage and freezing technique, ovulatory cycle (OC); artificial cycle (AC); weeks of gestation+days (WG+D), small for gestational age (SGA); large for gestational age (LGA)

The rate of birthweights $>4000 \mathrm{~g}$ was significantly higher in AC ( $16.3 \%$ vs. $2.7 \%, p=0.003$; adjusted- $p=0.015$ ) (not applicable for $>4500 \mathrm{~g}$, only 3 cases in AC, and none in OC). The rate of birthweights $<2500 \mathrm{~g}$ was lower in AC ( $3.5 \%$ vs. $11.6 \%$; $p=0.050$; adjusted- $p=0.049)$.

These discrepancies are highlighted in the rugplot and shift in birthweight density curves according to OC or AC preparation (Figure 1). When representing birthweight distribution in relation to gestational age at birth, the increased incidence of $>4000 \mathrm{~g}$ is objectified in extended terms $>41 \mathrm{WG}$, standing out in the AC group (Figure 2). SGA and LGA rates were not different. 


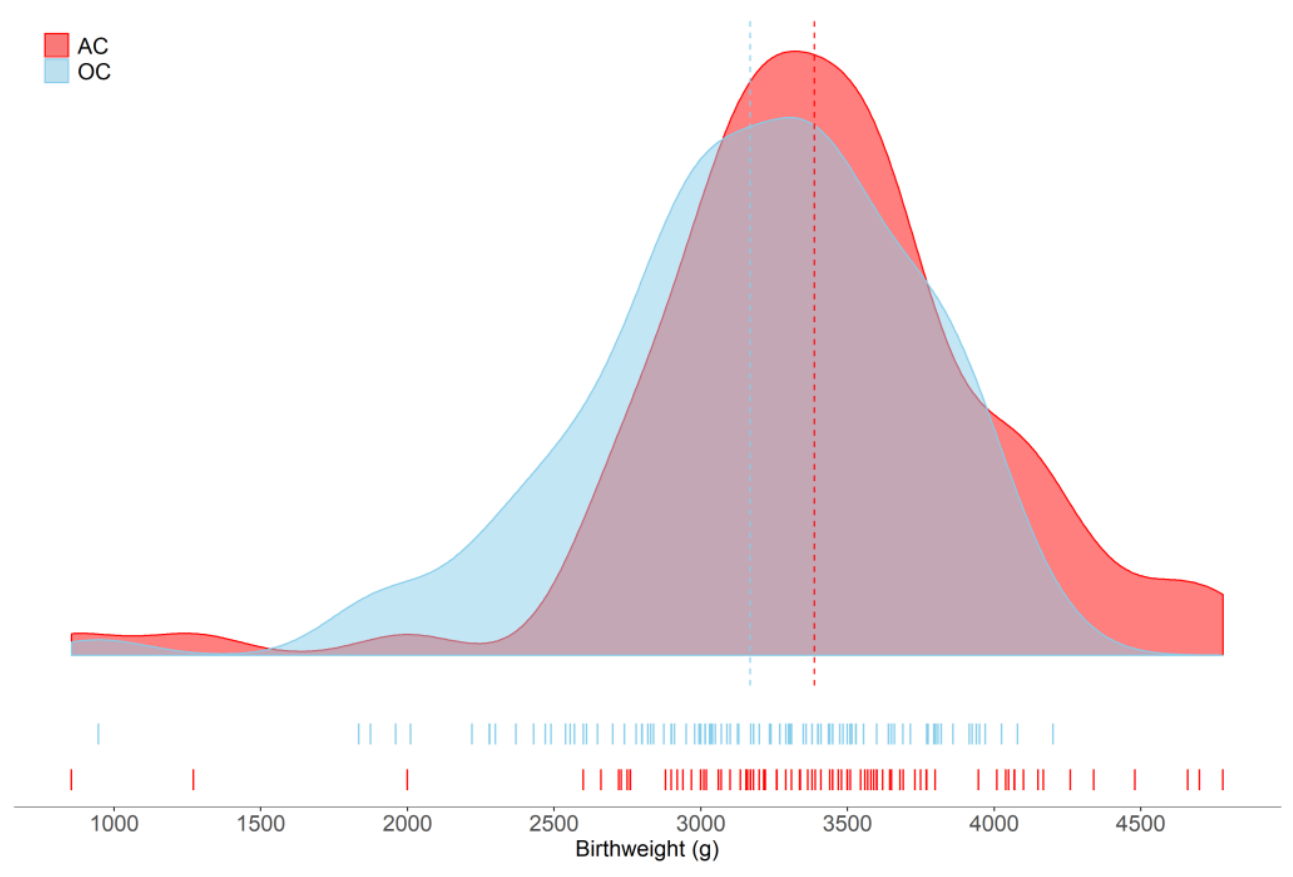

Figure1: Birthweight density curves and rugplot according to ovulatory (OC) or artificial (AC) endometrial preparation for FET (frozen embryo transfer)

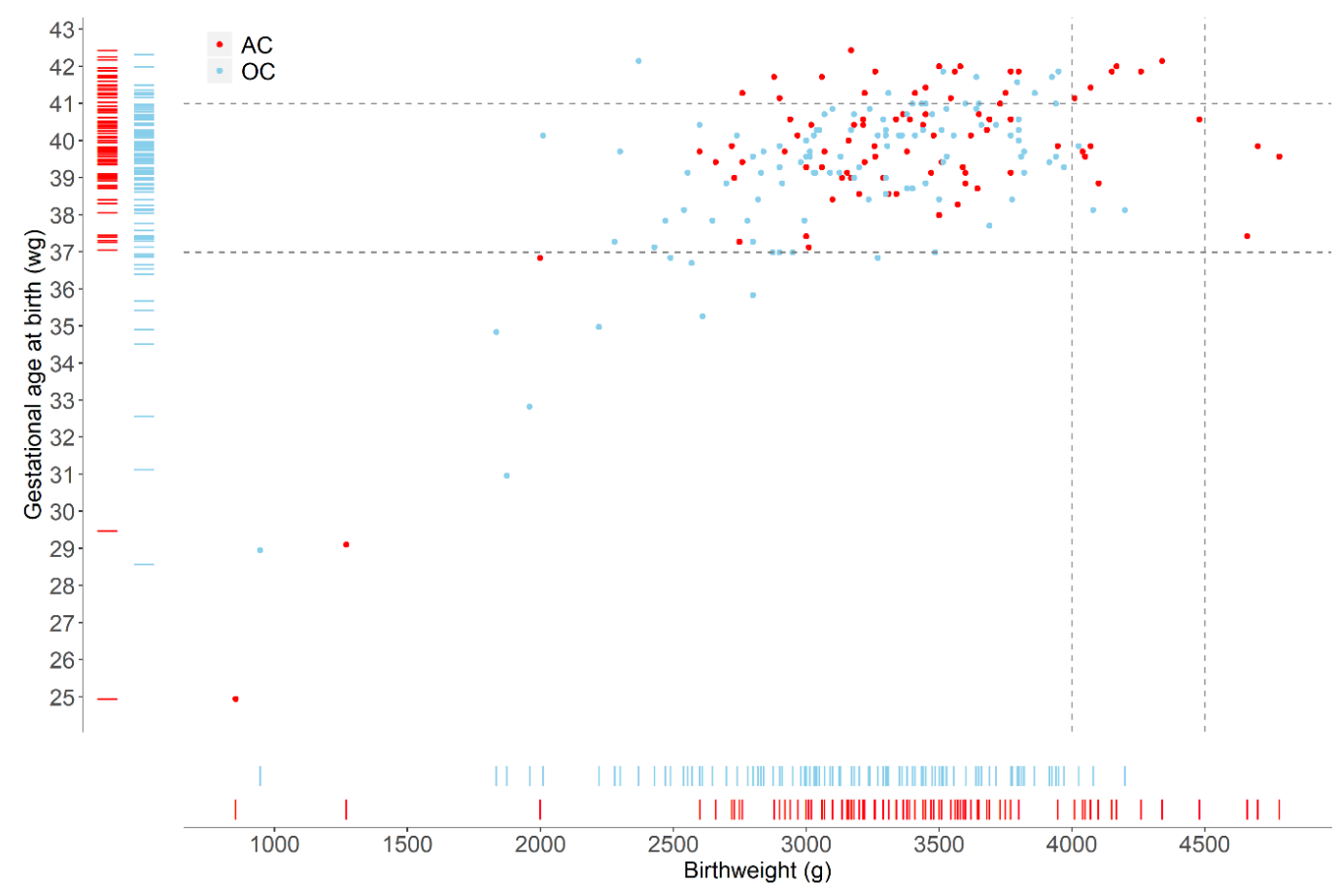

Figure 2: Birthweight and gestational age rugplots and scatterplot according to endometrial preparation for Frozen Embryo Transfer (FET) in ovulatory (OC) or artificial (AC) cycles and gestational age). Dotted lines represent $4000 \mathrm{~g}$ and $4500 \mathrm{~g}$ and $37 \mathrm{WG}$ and $41 \mathrm{WG}$.

\section{Discussion}

This retrospective analysis of neonatal outcomes of 198 singletons born after FET showed that endometrial preparation with AC was associated to higher birthweights and rates of 
birthweight $>4000 \mathrm{~g}$ compared to OC. These results remained significant after multivariate analysis. Among the maternal factors known to influence neonatal birth weight, BMI and parity were identical in both groups. PCOS, more frequent in the AC group, was included as an adjustment variable. Gestational age was not significantly different, nor were preterm or very pre-term birth rates. However, prolonged pregnancies $>41 \mathrm{WG}$ were significantly higher in AC, which may impact the increased birthweight observed $(+219 \mathrm{~g})$.

Our study focused on the difference in neonatal growth indicators according to treatments framing the early stages of embryo-fetal development. It is an exhaustive series comprising an all-round population over a 5-year period and mirroring daily clinical practice. Its monocentric character and limited period in time guarantees a stability and homogeneity of practitioners and protocols, enhancing comparability. Nevertheless, as a result of laboratory policy evolutions, different embryo stages and freezing protocols were included. Due to higher LBR observed with OC [11], clinical policies also evolved and endometrial preparation by OC became the privileged protocol for all patients with ovulatory cycles. AC was essentially prescribed in case of PCOS or history of failed OC. However, the 2 groups are comparable for most parental and embryonic characteristics (freezing technique, embryo stage, duration of conservation, e-SET). There was a concordance of significance without and with adjustment.

Unlike us, one of the first prospective randomized studies focusing on the influence of endometrial preparation on neonatal data by Cerillo et al.'s found no statistical difference in terms of weight and height of newborns in 570 FET cycles, of which n=280 AC and n=290 NC [36]. Nevertheless, the study comprised a very selected population, as it excluded women over 39, with severe endometriosis, or PCOS. Recently, Jing et al. [37] showed that AC was associated to higher birthweights compared to NC in multiple pregnancies (2550g vs. $2600 \mathrm{~g}$, respectively, $p=0.023)$. Consistently to our results, Ishii et al. [38] found significantly greater birthweights $(+137 \mathrm{~g}, p<0.01)$ after AC $(\mathrm{n}=403)$ compared to OC $(\mathrm{n}=$ 117). In blastocyst transfers, average birthweight was significantly higher in $\mathrm{AC}(p<0.01)$. For cleaved stage embryos, although not significant, average BW was higher in AC. Average BW from the AC-blastocyst transfers was, as described in our study, higher compared to OC-cleaved stage embryos $(p<0.01)$. Putative factors affecting BW such as stimulation protocols, stage and quality of embryos could not explain the difference observed.

To date, multiple findings indicate that FET leads to heavier babies compared to fresh transfers [12-19,21,23,26,37]. However, the underlying mechanisms remain unclear. The first hypotheses evoked were maternal factors and biological conditions. Vidal et al.'s [40] analysis including 14262 singletons births $>24$ WG suggested that maternal factors may play a role, as babies born from FET $(\mathrm{n}=1158)$ had significantly higher birthweights (+ $190 \mathrm{~g})$, lower LBW and SGA rates $(p<0.001)$ compared to fresh transfer $(\mathrm{n}=5560)$ in autologous cycles, while no difference was observed for egg donation transfers.

Conversely, the role of maternal factors was questioned by Pinborg et al. [21] in a study comparing FET $(\mathrm{n}=896)$ vs. fresh transfer $(\mathrm{n}=9480)$. Sibling pairs were analysed, where 
one singleton was born after FET and the consecutive sibling born after fresh transfer or vice versa. The adjusted Odds Ratio (AORs) of LGA and macrosomia in singletons were significant when conceived in FET vs. fresh transfer (1.34 [95\%CI 0.98-1.80] and 1.91 [95\%CI 1.40-2.62], respectively), and the increased risk was confirmed after adjustment on birth order. Therefore, results could not only be explained by being the second born, or by intrinsic maternal factors, but could also be related to freezing/thawing procedures per se.

Consistently, Anav et al. [41] suggested that cryopreservation in itself could be responsible of birthweight variations, independently of parity. Furthermore, animal studies such as the description of Big Calf Syndrome [42] and murine models focusing on the role of freezing techniques on genomic imprint showed that culture media constituents could affect birthweight, although no consensus exists concerning human data. Indeed, while Dumoulin et al. [43] and Nelissen et al. [28] showed a significant impact of embryo culture medium on early embryonic and fetal development and birthweight, no significant association was reported by Eaton et al. [44] and Vergouw et al. [45], even when adjusted for gestational age, gender and parity.

Concerning a possible influence of embryo stage on birthweight, Ishihara et al. [46] compared pregnancy outcomes between 4 groups: fresh Day $2(\mathrm{n}=10928)$; fresh Day $5(\mathrm{n}=$ 5981); vitrified-FET Day $2(\mathrm{n}=3841)$; vitrified-FET Day $5(\mathrm{n}=27408)$. FET was associated to lower LBW < 2500g and SGA, and to higher LGA rates (AOR 1.48). Lower rates of SGA and higher rates of LGA were observed for Day 5 vs. Day 2 embryos. Conversely, Belva et al. [47] found no influence of embryo stage on neonatal outcomes in live born singletons after fresh or FET cycles, although lower rates of SGA ( $p=0.005)$, higher rates of birthweight standard deviation score (SDS) $(p=0.008)$, length at birth SDS $(p=0.001)$, and head circumference SDS $(p=0.005)$ in FET groups were reported. The impact of endometrial preparation was not considered. Our work comprised more D5 and vitrified FET in OC than in AC group, but no difference in birthweight and LGA according to embryo stage was observed.

Although no transnational report exists on the proportion of protocols used for endometrial preparation, it seems that FET is mostly conducted using AC worldwide. However, using $\mathrm{AC}$ implies the continuous administration of $\mathrm{E} 2$ and progesterone during the first trimester of pregnancy. Specific attention should be paid to potential foetal effects of extended hormonal treatments, especially because epigenetic modifications can induce specific pathologies revealed decades after exposure. For instance, one must consider the dramatic consequences of diethylstilbestrol (DES) exposure during early pregnancy and its persistent effect in subsequent generations [48-51]. Unlike oocyte donation in which AC is mandatory to prepare embryo implantation, the choice of protocol remains open for FET. In case of endometrial preparation with $\mathrm{OC}$, a corpus luteum is active and progressively secretes progesterone until stabilisation of serum levels, leading to constant progesterone levels [52]. Moreover, ovulation triggering with hCG sustains the luteotropic effect in early luteal phase [53]. Finally, other factors are also secreted by the CL, leading to possibly more natural endometrial protein secretion profiles compared to AC [52], and recent findings 
suggest increased obstetrics risks in the absence of CL [54]. Besides maternal complications, adverse fetal outcomes such as stillbirth, shoulder dystocia, hypoglycemia, respiratory distress and perinatal mortality are increased in macrosomic babies, and further concerns during child- and adulthood include metabolic, cardiovascular and endocrine complications [55-58].

\section{Conclusions}

In conclusion, this study demonstrates that endometrial preparation by $\mathrm{AC}$ and its prolonged artificial hormonal environment during early foetal development in FET was significantly associated to higher mean birthweight, macrosomia and prolonged pregnancy rates compared to OC. The precautionary principle implies that the prevention of short or long term potential consequences of these neonatal characteristics, since possible, seems coherent. Since results obtained by OC do not strain the chances of pregnancy, and in the incomplete knowledge of the consequences of neonatal overweight on the future health of children, OC preparation could be advocated as first-line endometrial preparation in FET. Randomized controlled trials should be undertaken to assess these preliminary results.

Author Contributions: Conceptualization: SE, JL, MP; methodology: SE, XD, MP; software: SE, JL, SG, DL, XF; validation: SE, JL, DL, MP; formal analysis: SE; writing - original draft preparation: SE, JL, MP; writing - review and editing: SE, JL X.X.

All authors have read and agreed to the published version of the manuscript.

Funding: This research received no external funding.

Institutional Review Board Statement: The study was conducted according to the guidelines of the Declaration of Helsinki and approved by the Institutional Ethical Committee (CEERB Paris Nord, IRB 00006467: ID 2018-013).

Informed Consent Statement: According to French regulations, written informed consent from the patients was not required for this study. Patient consent was waived due to French regulations. All data were rendered anonymous before access and analysis.

Data Availability Statement: The data presented in this study are available on request from the corresponding author.

Conflicts of Interest: The authors declare no conflict of interest.

Acknowledgments: none.

\section{References}

1. Trounson, A.; Mohr, L. Human Pregnancy Following Cryopreservation, Thawing and Transfer of an Eight-Cell Embryo. Nature 1983, 305, 707-709, doi:10.1038/305707a0.

2. Agence de La Biomédecine Available online: https://rams.agence-biomedecine.fr/principaux-chiffres-delactivite-damp (accessed on 3 January 2020).

3. European IVF-monitoring Consortium (EIM); European Society of Human Reproduction and Embryology (ESHRE); Calhaz-Jorge, C.; De Geyter, C.; Kupka, M.S.; de Mouzon, J.; Erb, K.; Mocanu, E.; Motrenko, T.; 
Scaravelli, G.; et al. Assisted Reproductive Technology in Europe, 2013: Results Generated from European Registers by ESHRE. Hum. Reprod. 2017, 32, 1957-1973, doi:10.1093/humrep/dex264.

4. Kolibianakis, E.M.; Venetis, C.A.; Tarlatzis, B.C. Cryopreservation of Human Embryos by Vitrification or Slow Freezing: Which One Is Better? Curr. Opin. Obstet. Gynecol. 2009, 21, 270-274, doi:10.1097/GCO.0b013e3283297dd6.

5. Stehlik, E.; Stehlik, J.; Katayama, K.P.; Kuwayama, M.; Jambor, V.; Brohammer, R.; Kato, O. Vitrification Demonstrates Significant Improvement versus Slow Freezing of Human Blastocysts. Reprod. Biomed. Online 2005, 11, 53-57, doi:10.1016/s1472-6483(10)61298-9.

6. Liebermann, J.; Tucker, M.J. Comparison of Vitrification and Conventional Cryopreservation of Day 5 and Day 6 Blastocysts during Clinical Application. Fertil. Steril. 2006, 86, 20-26, doi:10.1016/j.fertnstert.2006.01.029.

7. Groenewoud, E.R.; Cantineau, A.E.P.; Kollen, B.J.; Macklon, N.S.; Cohlen, B.J. What Is the Optimal Means of Preparing the Endometrium in Frozen-Thawed Embryo Transfer Cycles? A Systematic Review and MetaAnalysis. Hum Reprod Update 2013, 19, 458-470, doi:10.1093/humupd/dmt030.

8. Ghobara, T.; Vandekerckhove, P. Cycle Regimens for Frozen-Thawed Embryo Transfer. Cochrane Database Syst Rev 2008, CD003414, doi:10.1002/14651858.CD003414.pub2.

9. Glujovsky, D.; Pesce, R.; Fiszbajn, G.; Sueldo, C.; Hart, R.J.; Ciapponi, A. Endometrial Preparation for Women Undergoing Embryo Transfer with Frozen Embryos or Embryos Derived from Donor Oocytes. Cochrane Database Syst Rev 2010, CD006359, doi:10.1002/14651858.CD006359.pub2.

10. Yarali, H.; Polat, M.; Mumusoglu, S.; Yarali, I.; Bozdag, G. Preparation of Endometrium for Frozen Embryo Replacement Cycles: A Systematic Review and Meta-Analysis. J Assist Reprod Genet 2016, 33, 1287-1304, doi:10.1007/s10815-016-0787-0.

11. Peigné, M.; Devouche, E.; Ferraretto, X.; Gricourt, S.; Luton, D.; Patrat, C.; Epelboin, S. Higher Live Birth Rate with Stimulated Rather than Artificial Cycle for Frozen-Thawed Embryo Transfer. Eur. J. Obstet. Gynecol. Reprod. Biol. 2019, 243, 144-149, doi:10.1016/j.ejogrb.2019.10.040.

12. Pessione, F.; De Mouzon, J.; Deveaux, A.; Epelboin, S.; Gervoise-Boyer, M.-J.; Jimenez, C.; Levy, R.; Valentin, M.; Viot, G.; Bergère, M.; et al. [Adverse obstetric and perinatal outcome with in vitro fertilization technology: a French nationwide population-based study]. Gynecol Obstet Fertil Senol 2020, doi:10.1016/j.gofs.2020.02.002.

13. Belva, F.; Henriet, S.; Van den Abbeel, E.; Camus, M.; Devroey, P.; Van der Elst, J.; Liebaers, I.; Haentjens, P.; Bonduelle, M. Neonatal Outcome of 937 Children Born after Transfer of Cryopreserved Embryos Obtained by ICSI and IVF and Comparison with Outcome Data of Fresh ICSI and IVF Cycles. Hum. Reprod. 2008, 23, 22272238, doi:10.1093/humrep/den254.

14. Shih, W.; Rushford, D.D.; Bourne, H.; Garrett, C.; McBain, J.C.; Healy, D.L.; Baker, H.W.G. Factors Affecting Low Birthweight after Assisted Reproduction Technology: Difference between Transfer of Fresh and Cryopreserved Embryos Suggests an Adverse Effect of Oocyte Collection. Hum. Reprod. 2008, 23, 1644-1653, doi:10.1093/humrep/den150.

15. Pinborg, A.; Loft, A.; Aaris Henningsen, A.-K.; Rasmussen, S.; Andersen, A.N. Infant Outcome of 957 Singletons Born after Frozen Embryo Replacement: The Danish National Cohort Study 1995-2006. Fertil. Steril. 2010, 94, 1320-1327, doi:10.1016/j.fertnstert.2009.05.091.

16. Pelkonen, S.; Koivunen, R.; Gissler, M.; Nuojua-Huttunen, S.; Suikkari, A.-M.; Hydén-Granskog, C.; Martikainen, H.; Tiitinen, A.; Hartikainen, A.-L. Perinatal Outcome of Children Born after Frozen and Fresh Embryo Transfer: The Finnish Cohort Study 1995-2006. Hum. Reprod. 2010, 25, 914-923, doi:10.1093/humrep/dep477. 
17. Wennerholm, U.-B.; Söderström-Anttila, V.; Bergh, C.; Aittomäki, K.; Hazekamp, J.; Nygren, K.-G.; Selbing, A.; Loft, A. Children Born after Cryopreservation of Embryos or Oocytes: A Systematic Review of Outcome Data. Hum. Reprod. 2009, 24, 2158-2172, doi:10.1093/humrep/dep125.

18. Wennerholm, U.-B.; Henningsen, A.-K.A.; Romundstad, L.B.; Bergh, C.; Pinborg, A.; Skjaerven, R.; Forman, J.; Gissler, M.; Nygren, K.G.; Tiitinen, A. Perinatal Outcomes of Children Born after Frozen-Thawed Embryo Transfer: A Nordic Cohort Study from the CoNARTaS Group. Hum. Reprod. 2013, 28, 2545-2553, doi:10.1093/humrep/det272.

19. Maheshwari, A.; Pandey, S.; Shetty, A.; Hamilton, M.; Bhattacharya, S. Obstetric and Perinatal Outcomes in Singleton Pregnancies Resulting from the Transfer of Frozen Thawed versus Fresh Embryos Generated through in Vitro Fertilization Treatment: A Systematic Review and Meta-Analysis. Fertil. Steril. 2012, 98, 368-377.e1-9, doi:10.1016/j.fertnstert.2012.05.019.

20. Sazonova, A.; Källen, K.; Thurin-Kjellberg, A.; Wennerholm, U.-B.; Bergh, C. Obstetric Outcome in Singletons after in Vitro Fertilization with Cryopreserved/Thawed Embryos. Hum. Reprod. 2012, 27, 1343-1350, doi:10.1093/humrep/des036.

21. Pinborg, A.; Henningsen, A.A.; Loft, A.; Malchau, S.S.; Forman, J.; Andersen, A.N. Large Baby Syndrome in Singletons Born after Frozen Embryo Transfer (FET): Is It Due to Maternal Factors or the Cryotechnique? Hum. Reprod. 2014, 29, 618-627, doi:10.1093/humrep/det440.

22. Pinborg, A.; Wennerholm, U.B.; Romundstad, L.B.; Loft, A.; Aittomaki, K.; Söderström-Anttila, V.; Nygren, K.G.; Hazekamp, J.; Bergh, C. Why Do Singletons Conceived after Assisted Reproduction Technology Have Adverse Perinatal Outcome? Systematic Review and Meta-Analysis. Hum. Reprod. Update 2013, 19, 87-104, doi:10.1093/humupd/dms044.

23. Kondapalli, L.A.; Perales-Puchalt, A. Low Birth Weight: Is It Related to Assisted Reproductive Technology or Underlying Infertility? Fertil. Steril. 2013, 99, 303-310, doi:10.1016/j.fertnstert.2012.12.035.

24. Nakashima, A.; Araki, R.; Tani, H.; Ishihara, O.; Kuwahara, A.; Irahara, M.; Yoshimura, Y.; Kuramoto, T.; Saito, H.; Nakaza, A.; et al. Implications of Assisted Reproductive Technologies on Term Singleton Birth Weight: An Analysis of 25,777 Children in the National Assisted Reproduction Registry of Japan. Fertility and Sterility 2013, 99, 450-455, doi:10.1016/j.fertnstert.2012.09.027.

25. Kalra, S.K.; Ratcliffe, S.J.; Barnhart, K.T.; Coutifaris, C. Extended Embryo Culture and an Increased Risk of Preterm Delivery. Obstet Gynecol 2012, 120, 69-75, doi:10.1097/AOG.0b013e31825b88fc.

26. Cooper, A.R.; O’Neill, K.E.; Allsworth, J.E.; Jungheim, E.S.; Odibo, A.O.; Gray, D.L.; Ratts, V.S.; Moley, K.H.; Odem, R.R. Smaller Fetal Size in Singletons after Infertility Therapies: The Influence of Technology and the Underlying Infertility. Fertil. Steril. 2011, 96, 1100-1106, doi:10.1016/j.fertnstert.2011.08.038.

27. Litzky, J.F.; Boulet, S.L.; Esfandiari, N.; Zhang, Y.; Kissin, D.M.; Theiler, R.N.; Marsit, C.J. Effect of Frozen/Thawed Embryo Transfer on Birthweight, Macrosomia, and Low Birthweight Rates in US Singleton Infants. American Journal of Obstetrics E Gynecology 2018, 218, 433.e1-433.e10, doi:10.1016/j.ajog.2017.12.223.

28. Nelissen, E.C.M.; van Montfoort, A.P.A.; Dumoulin, J.C.M.; Evers, J.L.H. Epigenetics and the Placenta. Hum. Reprod. Update 2011, 17, 397-417, doi:10.1093/humupd/dmq052.

29. Pinborg, A.; Wennerholm, U.B.; Romundstad, L.B.; Loft, A.; Aittomaki, K.; Söderström-Anttila, V.; Nygren, K.G.; Hazekamp, J.; Bergh, C. Why Do Singletons Conceived after Assisted Reproduction Technology Have Adverse Perinatal Outcome? Systematic Review and Meta-Analysis. Hum. Reprod. Update 2013, 19, 87-104, doi:10.1093/humupd/dms044.

30. Singh, B.; Reschke, L.; Segars, J.; Baker, V.L. Frozen-Thawed Embryo Transfer: The Potential Importance of the Corpus Luteum in Preventing Obstetrical Complications. Fertility and Sterility 2020, 113, 252-257, doi:10.1016/j.fertnstert.2019.12.007. 
31. Choux, C.; Ginod, P.; Barberet, J.; Rousseau, T.; Bruno, C.; Sagot, P.; Astruc, K.; Fauque, P. Placental Volume and Other First-Trimester Outcomes: Are There Differences between Fresh Embryo Transfer, Frozen-Thawed Embryo Transfer and Natural Conception? Reprod. Biomed. Online 2019, 38, 538-548, doi:10.1016/j.rbmo.2018.12.023.

32. Vashevnik, S.; Walker, S.; Permezel, M. Stillbirths and Neonatal Deaths in Appropriate, Small and Large Birthweight for Gestational Age Fetuses. Aust N Z J Obstet Gynaecol 2007, 47, 302-306, doi:10.1111/j.1479828X.2007.00742.x.

33. Glinianaia, S.V.; Obeysekera, M.A.; Sturgiss, S.; Bell, R. Stillbirth and Neonatal Mortality in Monochorionic and Dichorionic Twins: A Population-Based Study. Hum Reprod 2011, 26, 2549-2557, doi:10.1093/humrep/der213.

34. Grisaru-Granovsky, S.; Reichman, B.; Lerner-Geva, L.; Boyko, V.; Hammerman, C.; Samueloff, A.; Schimmel, M.S.; Israel Neonatal Network Mortality and Morbidity in Preterm Small-for-Gestational-Age Infants: A Population-Based Study. Am. J. Obstet. Gynecol. 2012, 206, 150.e1-7, doi:10.1016/j.ajog.2011.08.025.

35. Vayssière, C.; Haumonte, J.-B.; Chantry, A.; Coatleven, F.; Debord, M.P.; Gomez, C.; Le Ray, C.; Lopez, E.; Salomon, L.J.; Senat, M.V.; et al. Prolonged and Post-Term Pregnancies: Guidelines for Clinical Practice from the French College of Gynecologists and Obstetricians (CNGOF). Eur. J. Obstet. Gynecol. Reprod. Biol. 2013, 169, 1016, doi:10.1016/j.ejogrb.2013.01.026.

36. Cerrillo, M.; Herrero, L.; Guillén, A.; Mayoral, M.; García-Velasco, J.A. Impact of Endometrial Preparation Protocols for Frozen Embryo Transfer on Live Birth Rates. Rambam Maimonides Med J 2017, 8, doi:10.5041/RMMJ.10297.

37. Jing, S.; Li, X.F.; Zhang, S.; Gong, F.; Lu, G.; Lin, G. Increased Pregnancy Complications Following FrozenThawed Embryo Transfer during an Artificial Cycle. J. Assist. Reprod. Genet. 2019, 36, 925-933, doi:10.1007/s10815-019-01420-1.

38. Ishii, R.; Shoda, A.; Kubo, M.; Okazaki, S.; Suzuki, M.; Okawa, R.; Enomoto, M.; Shitanaka, M.; Fujita, Y.; Nakao, K.; et al. Identifying a Possible Factor for the Increased Newborn Size in Singleton Pregnancies after Assisted Reproductive Technology Using Cryopreserved Embryos, in Comparison with Fresh Embryos. Reprod Med Biol 2018, 17, 307-314, doi:10.1002/rmb2.12206.

39. Pinborg, A.; Loft, A.; Henningsen, A.-K.A.; Ziebe, S. Does Assisted Reproductive Treatment Increase the Risk of Birth Defects in the Offspring? Acta Obstetricia et Gynecologica Scandinavica 2012, 91, 1245-1246, doi:10.1111/j.1600-0412.2012.01500.x.

40. Vidal, M.; Vellvé, K.; González-Comadran, M.; Robles, A.; Prat, M.; Torné, M.; Carreras, R.; Checa, M.A. Perinatal Outcomes in Children Born after Fresh or Frozen Embryo Transfer: A Catalan Cohort Study Based on 14,262 Newborns. Fertility and Sterility 2017, 107, 940-947, doi:10.1016/j.fertnstert.2017.01.021.

41. Anav, M.; Phillips, S.; Ferrieres-Hoa, A.; Gala, A.; Fournier, A.; Vincens, C.; Vintejoux, E.; Maris, E.; Grysole, C.; Bissonnette, F.; et al. Cryopreserved Embryo Replacement Is Associated with Higher Birthweight Compared with Fresh Embryo: Multicentric Sibling Embryo Cohort Study. Scientific Reports 2019, 9, 1-7, doi:10.1038/s41598019-49708-7.

42. Young, L.E.; Sinclair, K.D.; Wilmut, I. Large Offspring Syndrome in Cattle and Sheep. Rev. Reprod. 1998, 3, 155163, doi:10.1530/ror.0.0030155.

43. Dumoulin, J.C.; Land, J.A.; Van Montfoort, A.P.; Nelissen, E.C.; Coonen, E.; Derhaag, J.G.; Schreurs, I.L.; Dunselman, G.A.; Kester, A.D.; Geraedts, J.P.; et al. Effect of in Vitro Culture of Human Embryos on Birthweight of Newborns. Hum. Reprod. 2010, 25, 605-612, doi:10.1093/humrep/dep456.

44. Eaton, J.L.; Lieberman, E.S.; Stearns, C.; Chinchilla, M.; Racowsky, C. Embryo Culture Media and Neonatal Birthweight Following IVF. Hum. Reprod. 2012, 27, 375-379, doi:10.1093/humrep/der381. 
45. Vergouw, C.G.; Kieslinger, D.C.; Kostelijk, E.H.; Botros, L.L.; Schats, R.; Hompes, P.G.; Sakkas, D.; Lambalk, C.B. Day 3 Embryo Selection by Metabolomic Profiling of Culture Medium with Near-Infrared Spectroscopy as an Adjunct to Morphology: A Randomized Controlled Trial. Hum. Reprod. 2012, 27, 2304-2311, doi:10.1093/humrep/des175.

46. Ishihara, O.; Araki, R.; Kuwahara, A.; Itakura, A.; Saito, H.; Adamson, G.D. Impact of Frozen-Thawed SingleBlastocyst Transfer on Maternal and Neonatal Outcome: An Analysis of 277,042 Single-Embryo Transfer Cycles from 2008 to 2010 in Japan. Fertil. Steril. 2014, 101, 128-133, doi:10.1016/j.fertnstert.2013.09.025.

47. Belva, F.; Bonduelle, M.; Roelants, M.; Verheyen, G.; Van Landuyt, L. Neonatal Health Including Congenital Malformation Risk of 1072 Children Born after Vitrified Embryo Transfer. Hum Reprod 2016, 31, 1610-1620, doi:10.1093/humrep/dew103.

48. Tournaire, M.; Epelboin, S.; Devouche, E. [Diethylstilbestrol story]. Therapie 2014, 69, 101-114, doi:10.2515/therapie/2014012.

49. Tournaire, M.; Devouche, E.; Espié, M.; Asselain, B.; Levadou, A.; Cabau, A.; Dunbavand, A.; Grosclaude, P.; Epelboin, S. Cancer Risk in Women Exposed to Diethylstilbestrol in Utero. Therapie 2015, 70, 433-441, doi:10.2515/therapie/2015030.

50. Tournaire, M.; Epelboin, S.; Devouche, E.; Viot, G.; Le Bidois, J.; Cabau, A.; Dunbavand, A.; Levadou, A. Adverse Health Effects in Children of Women Exposed in Utero to Diethylstilbestrol (DES). Therapie 2016, 71, 395-404, doi:10.1016/j.therap.2016.01.006.

51. Wautier, A.; Tournaire, M.; Devouche, E.; Epelboin, S.; Pouly, J.-L.; Levadou, A. Genital Tract and Reproductive Characteristics in Daughters of Women and Men Prenatally Exposed to Diethylstilbestrol (DES). Therapie 2019, doi:10.1016/j.therap.2019.10.004.

52. Casper, R.F.; Yanushpolsky, E.H. Optimal Endometrial Preparation for Frozen Embryo Transfer Cycles: Window of Implantation and Progesterone Support. Fertility and Sterility 2016, 105, 867-872, doi:10.1016/j.fertnstert.2016.01.006.

53. Fauser, B.C.; de Jong, D.; Olivennes, F.; Wramsby, H.; Tay, C.; Itskovitz-Eldor, J.; van Hooren, H.G. Endocrine Profiles after Triggering of Final Oocyte Maturation with GnRH Agonist after Cotreatment with the GnRH Antagonist Ganirelix during Ovarian Hyperstimulation for in Vitro Fertilization. J. Clin. Endocrinol. Metab. 2002, 87, 709-715, doi:10.1210/jcem.87.2.8197.

54. Saito, K.; Kuwahara, A.; Ishikawa, T.; Morisaki, N.; Miyado, M.; Miyado, K.; Fukami, M.; Miyasaka, N.; Ishihara, O.; Irahara, M.; et al. Endometrial Preparation Methods for Frozen-Thawed Embryo Transfer Are Associated with Altered Risks of Hypertensive Disorders of Pregnancy, Placenta Accreta, and Gestational Diabetes Mellitus. Hum. Reprod. 2019, 34, 1567-1575, doi:10.1093/humrep/dez079.

55. Gu, S.; An, X.; Fang, L.; Zhang, X.; Zhang, C.; Wang, J.; Liu, Q.; Zhang, Y.; Wei, Y.; Hu, Z.; et al. Risk Factors and Long-Term Health Consequences of Macrosomia: A Prospective Study in Jiangsu Province, China. J Biomed Res 2012, 26, 235-240, doi:10.7555/JBR.26.20120037.

56. Ornoy, A. Prenatal Origin of Obesity and Their Complications: Gestational Diabetes, Maternal Overweight and the Paradoxical Effects of Fetal Growth Restriction and Macrosomia. Reprod. Toxicol. 2011, 32, 205-212, doi:10.1016/j.reprotox.2011.05.002.

57. Metabolic Syndrome in Childhood: Association With Birth Weight, Maternal Obesity, and Gestational Diabetes Mellitus I American Academy of Pediatrics Available online: https://pediatrics.aappublications.org/content/115/3/e290 (accessed on 20 February 2020).

58. Jenner, Z.B.; O'Neil Dudley, A.E.; Mendez-Figueroa, H.; Ellis, V.S.; Chen, H.-Y.; Chauhan, S.P. Morbidity Associated with Fetal Macrosomia among Women with Diabetes Mellitus. Am J Perinatol 2018, 35, 515-520, doi:10.1055/s-0037-1608811. 
